\title{
DETERMINANTS OF REGIONAL DIFFERENCES IN SICK LEAVE DURATION FOR HOMOGENEOUS GROUPS IN THE NETHERLANDS: THEIR IMPLICATIONS FOR SOCIAL SECURITY POLICY-MAKING
}

\author{
Willibrord Beemsterboer ${ }^{1}$, Roy Stewart ${ }^{2}$, J ohan Groothoff', Frans Nijhuis ${ }^{1}$ \\ Department of Health Organisation, Policy and Economics, University of Maastricht, the Netherlands \\ 2Department of Health Sciences, University Medical Center Groningen, University of Groningen, the Netherlands
}

\begin{abstract}
SUMMARY
Objectives: Regional differences in sick leave duration determinants were studied between in age and profession homogeneous groups in different regions in the Netherlands, i.e. Utrecht and Southern Limburg, in order to find any effects of socio-cultural factors.

Material and methods: 137 participants in Utrecht and Southern Limburg were interviewed. Data of sick leave duration were obtained from the social fund.

Results: A statistical comparison of sick leave duration figures showed that, in Southern Limburg, determinants of 'health status' (questions about perceived health and burnout due to work) and 'individual characteristics and circumstances' (age, gender and satisfaction with private circumstances) were associated with sick leave duration and, in Utrecht, the 'work contents' determinant autonomy.

Conclusions: In the regions studied, different determinants appeared to be associated with sick leave duration and for some of them the European integration was assumed to have a lasting effect. Nationwide policy interventions to reduce sick leave duration should take into account the existence of regional differences in determinants predicting sick leave duration and the potential effects of different socio-cultural characteristics on laying claim to social security.
\end{abstract}

Key words: regions, sick leave duration, determinants, social security policy

Address for corres pondence: W. G. M. Beemsterboer, Hoogbrugstraat 20-B, 6221 CR Maastricht, the Netherlands.

E-mail: willibrordbeemsterboer@ uwnet.nl

\section{INTRODUCTION}

Different socio-cultural characteristics of different regions may play a role in the type of determinants that affect sick leave. This was the result of a study which explored regional differences in sick leave with regard to relevant determinants of sick leave duration (1).

Sick leave duration is associated with many determinants, whereas little is known about region-related factors that possibly play a role in the type of determinants that predominate. Generally, sick leave is associated with illness although the perception of health may differ between or within countries, which may result in different outcomes in sick leave and disability rates. As for differences in health-related determinants between countries, the European Labour Force Survey (2) showed remarkable differences in national percentages of people with self-reported disabilities (Table 1).

Large differences were found between European countries both in individual health perception and in the number of people having disabilities or long-standing health problems. In Ireland, Austria, Slovenia, Norway, Portugal and Denmark 15-30\% of the employees perceive themselves as having disabilities or long-standing health problems, while in France, the Netherlands, Finland and the United Kingdom this is even more than $30 \%$.
As for sick leave, Prins (3) performed a study on differences between Belgium, Germany and the Netherlands which showed that cultural differences attributed to differences in sickness behaviour. The author stated that considerable regional differences in lifestyle, health care and economic factors may underlay the general sickness absence levels, including regional differences that were found in the German sick fund (4). Prins (3) also found that sick leave rates were poor indicators of illness and that culture, in the sense of an attitude towards legislation and avoiding uncertainty, produced differences in sick leave behaviour and in regulations for compensating loss of wages. This about the differences in disabilities and sick leave found between countries.

As for differences in sick leave between regions within the same country research appears to be scarce. The most important outcome of studies on regional differences in duration of sick leave is that they are the result of socio-economic class differences or circumstances and development (5-11). Tordoir et al. (12) and Soeters (13) found a longer duration of sick leave in the Dutch region of Southern Limburg as compared to the rest of the country and the regional organisation of health services (e.g. waiting-period before treated effectively) was held responsible for this. Later figures showed that the Limburg area still had a more prolonged sick leave duration $(14,15)$, despite better organised regional health services (the founding of the Academic Hospital Maastricht in the 
Table 1. Persons with self-reported disabilities $(P w d)$ in various circumstances and in different European countries

\begin{tabular}{|c|c|c|c|c|c|c|c|c|c|c|c|c|c|c|}
\hline & $\frac{\pi}{8}$ & है & $\begin{array}{l}\overline{8} \\
\frac{\pi}{2} \\
\frac{1}{2}\end{array}$ & 8 & है & $\begin{array}{l}\bar{z} \\
\underline{\underline{e}}\end{array}$ & $\frac{\lambda}{14}$ & $\frac{9}{\sum}$ & 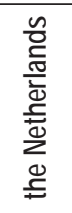 & 商 & $\begin{array}{l}8 \\
8 \\
8\end{array}$ & $\begin{array}{l}\frac{8}{8} \\
\frac{8}{6} \\
\text { ज }\end{array}$ & $\frac{8}{3}$ & $\begin{array}{l} \\
\frac{8}{8} \\
\frac{8}{8} \\
\frac{8}{8} \\
\frac{8}{3}\end{array}$ \\
\hline Pwd (persons with disability) & $12.7^{*}$ & 19.9 & 32.0 & 23.6 & 10.0 & 10.8 & 6.6 & 8.5 & 25.3 & 16.3 & 19.7 & 8.2 & 19.5 & 25.0 \\
\hline Pwd working & 19.0 & 28.7 & 45.3 & 35.0 & 13.3 & 17.0 & 8.8 & 12.0 & 41.0 & 24.4 & 26.6 & 9.8 & 25.4 & 40.4 \\
\hline Pwd disability pensions & 3.5 & 7.0 & 4.8 & 4.7 & 3.7 & 2.0 & 0.0 & 0.0 & 8.1 & 0.0 & 0.0 & 6.1 & 0.0 & 3.7 \\
\hline
\end{tabular}

* National percentages

1990s), and demonstrated differences in health between the Dutch province of Limburg and the rest of the country (16-20). In their Euregional study Stevens and Van der Zee (16) hypothesised health attitude effects from the neighbouring German state of NordrheinWestfalen (NRW) on the people of Southern Limburg, especially regarding doubts about their personal health. The study of Stevens and Van der Zee (16) was focussed on the Euregion Meuse-Rhine $(E M R)$, with assumed socio-cultural influences on the Southern Limburg area from the adjacent countries, i.e. Belgium (provinces Limburg and Liège) and Germany (NRW).

The study presented here aims to examine regional differences in sick leave duration between geographically and socio-culturally different regions in the Netherlands - one of them being part of an Euregion - to discover possible effects of regional socio-cultural differences on sick leave behaviour. Since sick leave duration is influenced by various determinants, what we needed for this study was: a) at least two geographically and socio-culturally different regions, b) sick leave data of those regions, c) relevant sick leave duration determinants that are effective. A literature search was performed to define a set of relevant sick leave duration determinants.

\section{Regions, Socio-cultural Characteristics and Health and Sick Leave Behaviour}

Soeters (13) found that regional differences in sick leave were the result of regional differences in the organisation of health services, but according to this author other factors could play a role as well, e.g. the extent of medical consumption. Soeters found that the mean duration of sick leave in the Dutch province of Limburg was longer than in the rest of the country.

Soeters (13) as well as Prins (3) referred to studies by Hofstee (21) and Hofstede (22) in which the existence of regional differences in death rates and medical consumption was assumed. Those differences were attributed to cultural characteristics of the local inhabitants. Lifestyle factors like for instance eating habits and smoking and drinking alcohol have an influence on people's health and, consequently, on sick leave behaviour. This observation is in accordance with the outcome of international research $(9,11)$.

Sick leave is related with illness $(8,23,24)$ as it is with behaviour (25-27) and therefore subject to socio-cultural factors such as habits, traditions and moral standards. Consequently, people perceive their health or their work situation differently, i.e. make different choices under comparable circumstances. Thus, sick leave is often associated with a certain freedom to decide for or against taking it. Regional socio-cultural characteristics may influence this decision. As socio-cultural factors may influence the perception of the work situation and the perception of one's health, there may be regional differences in health status or in diseases as well as in morbidity and mortality rates (19). When areas situated in Euregions are involved, these factors may also be influenced by socio-cultural characteristics from the neighbouring country and this effect may even increase as a result of developing European integration. As a matter of fact, the removal of internal European checkpoints and border control (Schengen Treaty, 1985) has undoubtedly attributed to a more intensive interaction between the different populations in Euregions and is very likely to sustain and stimulate mutual influence.

Factors of culture and social tradition, or lifestyle, are supposed to influence the health status of communities $(21,22)$. Hofstede (22) defined the cultural identity of a population as a collective 'programme' of the mind that discriminates groups from one another. Culture is a common characteristic of groups on the level of a family or a region, expressed through the way people behave or through their opinions (16). Stevens and Van der Zee (16) compared Nordrhein-Westfalen with both Limburg and the rest of the Netherlands. According to Hofstede (22), since Germans tend to feel awkward in coping with uncertainty they are more concerned about their health than the Dutch; this is why Germans consult their doctor more frequently. Southern Limburg residents perceive themselves in poorer health than their countrymen and this, together with a less healthy lifestyle, stimulates medical consumption and, probably, sick leave.

Health status is not a good predictor of sick leave $(8,23,24)$. Therefore the assumption is that socio-cultural factors play a role in sick leave behaviour. The theoretical model is as follows (Fig. 1).

Taking the view that sick leave determinants as such are universal, the assumption is that the fact that people have different socio-cultural backgrounds leads to different determinants having their effects in a population.

\section{Research Question}

We could not find any studies which compared the relation between similar sets of relevant determinants of sick leave duration and the duration of sick leave for different regions of the Netherlands and no study reflected on possible (Eu)regional socio-cultural influences on the differences found.

Thus, the research question was defined as follows: Are there any differences in the determinants of sick leave duration between homogeneous groups in socio-culturally different regions within a single country and what evidence can be found to suggest an effect of the regional socio-cultural environment? 
Table 2. Sick leave duration independent of profession in five districts of a Dutch social fund (Detam, 1991)

\begin{tabular}{|l|c|c|c|c|c|}
\hline & Groningen & Amsterdam & Utrecht & The Hague & $\begin{array}{c}\text { Heerlen } \\
\text { (Southern Limburg) }\end{array}$ \\
\hline Mean sick leave duration (days) & 23.95 & 23.08 & 23.13 & 19.57 & 29.23 \\
\hline
\end{tabular}

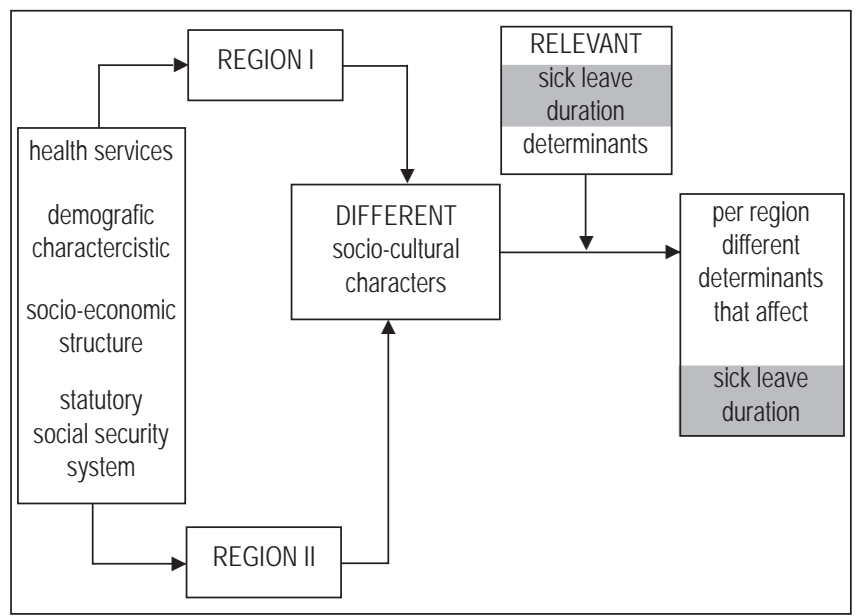

Fig. 1. Theoretical model

The first part of the research question was divided into five subquestions: 1. How does sick leave duration compare between homogeneous groups in different regions? 2. How do scores of individual sick leave duration determinants compare between homogeneous groups in different regions? 3. How does sick leave duration relate to relevant determinants between homogeneous groups in different regions? 4. What differences in determinants predicting sick leave duration can be found between homogeneous groups in different regions? 5. Are the determinants in which regions differ correlated?

To answer these questions a literature review was needed to identify the determinants of sick leave duration that were found until the early 1990s. The aim was to define a set of relevant determinants. In order to increase the study's topical interest it was also considered useful to review the literature from the early 1990s onwards. The review referred to several Dutch studies on determinants of sick leave duration until October 1993 (28-31). For later years, both national and international scientific journals, academic theses and Medline were consulted ${ }^{1}$.

After reviewing the literature on sick leave duration we concluded that, during the last few decades, a broad range of sick leave duration determinants was mentioned in a highly consistent pattern. This conclusion was based on the finding that studies on sick leave duration during the years 1984-2004 apparently focussed on similar determinants.

The literature search was performed in order to identify a set of relevant determinants. Identifying these determinants was merely a means to achieve the main purpose of the present study, i.e. to find any differences in effective sick leave duration determinants between regions based on their socio-cultural differences. Thus our study, focussed primarily on socio-cultural differences as a cause of regional differences in active sick leave duration determinants, was not a study on sick leave duration determinants as such.
Table 3. Disability pension rates (Limburg and the Netherlands)

\begin{tabular}{|l|c|c|}
\hline & Limburg & the Netherlands \\
\hline \% disability pension $1986^{1}$ & 9.5 & 6.8 \\
\hline \% disability pension $2000^{2}$ & 10.7 & 8.8 \\
\hline \% disability pension $2003^{3}$ & 11.1 & 8.9 \\
\hline \% disability pension $2005^{3}$ & 10.1 & 8.0 \\
\hline
\end{tabular}

${ }^{1}$ Bisscheroux et al. (1986)

${ }^{2}$ Nationaal Kompas Volksgezondheid 2001-2003 [National Public Health Compass 2001-2003] (RIVM 2006)

${ }^{3}$ Atlas Sociale Verzekeringen 2003/2005 [Social Insurance Atlas 2003/2005] (UWV 2005)

\section{MATERIAL AND METHODS}

\section{Registration of Sick Leave Data}

One of the authors worked for a social fund (i.e. Detam) which registered - although for specific professional groups only (sale, cleaning, trade) - the duration of sick leave per region. This made it possible to compare the relations between relevant determinants of sick leave duration and the duration of sick leave registered per region. Remarkable regional differences in sick leave duration were observed (Table 2).

\section{Regions and Professions Studied}

In order to compare sick leave between different regions of our country, it was necessary to select those specific regions.

Tordoir et al. (12) and Soeters (13) found differences between the region of Southern Limburg and the rest of the Netherlands, the Southern Limburg area being part of the Euregion Meuse-Rhine (EMR). Southern Limburgers appear to have a less healthy lifestyle than their countrymen. Their body weight is higher (32) and they engage in less physical exercise (19). Traditionally, Southern Limburgers drink more alcohol and show more tobacco addiction, although smoking is decreasing (19). Limburgers perceived their health status as relatively poor (33). The Nationaal Kompas Volksgezondheid 2001-2003 (National Public Health Compass 2001-2003, 2006) (34) showed that 20-25\% of the Limburgers still perceive themselves to be in relatively poor health, which was more than in any other part of the country. Besides disability rates in 2000, 2003 and 2005 were higher in Limburg and over the years they increased simultaneously with raising national rates $(34,35)$ (Table 3).

Taking into account the deviating regional sick leave duration figures in Southern Limburg versus the rest of the country, the high disability rates in this region, its different lifestyle, a different

${ }^{1}$ Literature is sent by the corresponding author on request. 
socio-cultural history (the area was ruled by surrounding principalities until 1830 and consequently influenced by German and Flemish/Wallonian socio-cultural traditions) as well as a growing Euregional influence from adjacent countries (Schengen Treaty, 1985) and, finally, the different perception of health status, we considered the Southern Limburg population as socio-culturally different from the rest of the Netherlands. Thus, for obvious reasons, it was decided to compare the region of Southern Limburg with one of the other regions of our country.

We mentioned some remarkable differences in health status between the province of Limburg and the rest of the Netherlands. As to find another region for comparison purposes practical considerations dominated, more specifically the central position of the city of Utrecht and this city being the residence of the Detam social fund. Additionally using the region Utrecht i.e. the city of Utrecht and its immediate surroundings for making comparisons with Southern Limburg, was motivated by sick leave duration figures from Detam showing differences between the Utrecht and Southern Limburg regions (Table 2). The comparable mixture of urban and rural qualities of the two regions, Southern Limburg including the cities of Heerlen and Maastricht, as well as their socio-economic comparability were all the more reason to compare them in terms of sick leave behaviour.

As the cleaning profession showed marked differences in sick leave duration between Utrecht and Southern Limburg, this profession was selected to make comparisons between the two regions.

\section{Participants}

Workers were included in the study population as soon as they reported sick and unable to work. This was the best possible moment because most of those reporting sick (>95\%) were visited by a controlling official within one week.

In order to exclude specific effects of younger ( $<20$ years) or older ( $>40$ years) subjects on the results and to enhance the homogeneity of the study group, the participants had to be between 20 and 40 years old and their reasons for reporting sick had to be 'low back pain' or 'uncomplicated stress'. The decision to use these diagnostic categories had a pragmatic basis: by using these commonly found diagnoses which - other than specific diseases - leave the subject much freedom to act, it was assumed that a substantial number of participants (at least 50 to 100 per region) could be recruited within a relatively short period of time (6 months). 137 employees (52 in Utrecht, 85 in Southern Limburg) agreed to participate. This number was the outcome of an interview period of six months based on a random procedure in which every next employee meeting the requirements was asked to participate. All employees who agreed to participate $(N=137)$ really did participate in the study.

The responding and non-responding groups did not differ as far as age, gender or level of education were concerned. Strictly individual characteristics such as age and gender were the only determinants of the non-responding group to be included in the statistical analysis.

\section{Questionnaire}

Some data on the individual and work characteristics of participants were derived from a specific form which was completed by the employer and sent to the social fund to report the first day of sick leave. When employees agreed to participate, a booklet with questions was handed out which they were asked to answer. In accordance with the results of the literature review until the early 1990s, the booklet presented questions that referred to the determinants identified. The questions were derived from the validated VAG (Vragenlijst Arbeid en Gezondheid, Work and Health Questionnaire) (36).

Figure 2 presents the origins of the questions. The figure reflects the finding that the results of the literature review showed a remarkable consistency over the years 1984-2004.

Determinants belonging to similar categories were combined. Thus, the categorised determinants constitute the independent variables while duration of sick leave is the dependent variable. Parameters of social and demographic developments were not investigated because legal, political and socio-economic status and developments were similar throughout the country and the study population was homogeneous.

The selected determinants were used as the basis for statistical analysis.

In Southern Limburg 68\% of the distributed booklets was returned, in Utrecht this was $75 \%$.

\section{Time Line}

A study of the mean duration of sick leave requires a certain period of registration which, in the present study, was the year preceding the day of reporting sick. For those reporting sick on the first of October, 1991, we referred to the period starting on the first of October, 1990; for those reporting sick on the first of December, 1991, we referred to the period starting on the first of December, 1990, and so on. The mean duration of sick leave in the referred year was used in the analysis. As a result, the time line of the study, including the 12-month period preceding the spell of sick leave, was as follows:

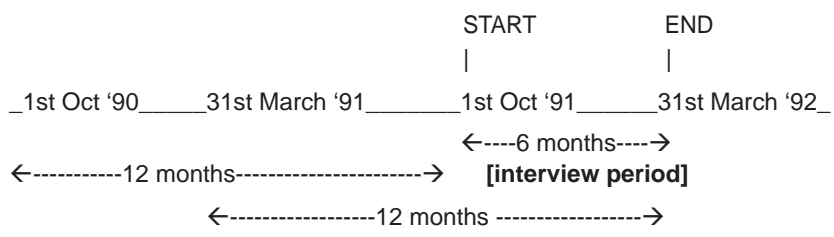

\section{Determinants and Study Design}

The collected answers (items) were classified for statistical purposes and, based on a factor analysis (not presented here), combined to form compound determinants. Table 4 provides a classification of the determinants in accordance with those in Fig. 2; it also presents the number of items as well as Cronbach's $\alpha$ for compound determinants.

The level of Cronbach's $\alpha$ was fixed on 0.70 as this was a rather safe procedure in the sense that the value is less dependent on the number of items (constituting the compound determinant) than if higher levels are used (37). A few compound determinants lacked internal coherence (Cronbach's $\alpha<0.70$ ) and were eliminated. They were 'pollution at the workplace' and 'air climate/pollution' of the work circumstances. Figure 3 presents the study design.

The relations between similar sets of sick leave duration determinants, on the one hand, and sick leave, on the other, were analysed for homogeneous groups in Utrecht and Southern Limburg. The resulting outcomes for the two regions were then compared. 


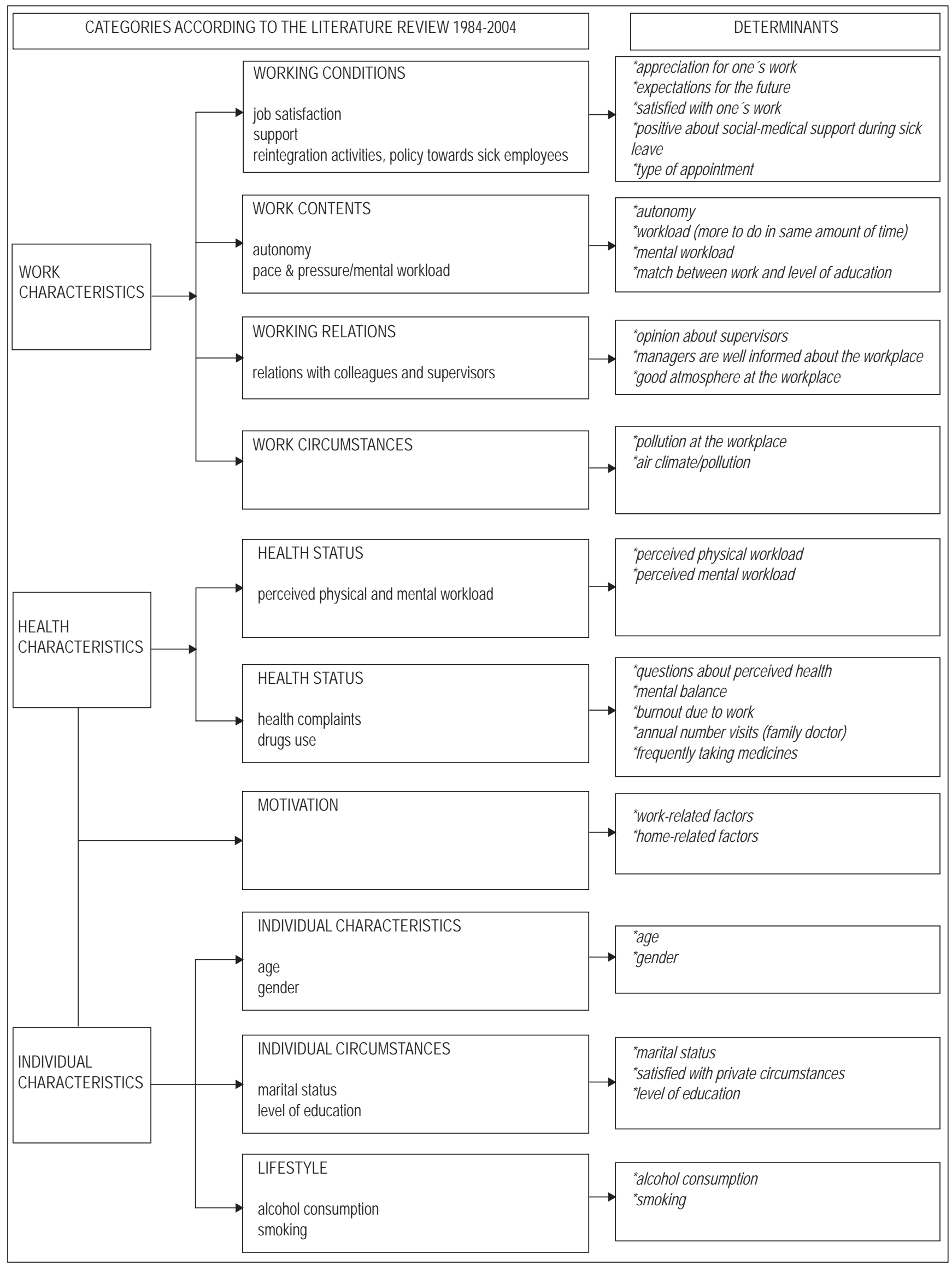

Fig. 2. Categories according to the literature review 1984-2004/Determinants of sick leave duration. 


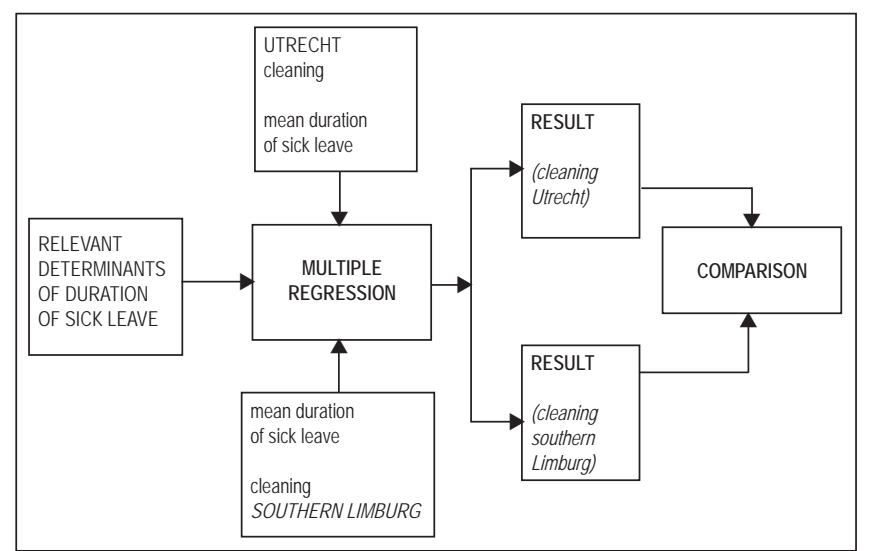

Fig. 3. Design of the study.

\section{Statistical Analysis}

The statistical analysis included: a) a dependent group $t$ test; b) an independent sample $t$ test; c) regression analyses per region; d) a comparison of the regression coefficients for the two regions (38); and e) a regression analysis in order to find any correlations between the determinants in which the regions differ.

A missing data analysis was performed to find out whether the number of missing data might affect the results. If so, imputation was applied. Consequently, the potential effect of missing data on the outcome was estimated. A box plot was performed to check the potential effect of extreme/outlying scores on the outcome. A significance level of $p<0.05$ was applied.

\section{RESULTS}

As far as demographic data were concerned, the average age in Southern Limburg was 33.5 years, in Utrecht 33.2 years. In Southern Limburg the percentage of female participants was $82 \%$, in Utrecht 73\%; in both regions, the majority of participants had low levels of education (vocational school level): Southern Limburg 96\%, Utrecht 95\%. Thus, the two study populations were remarkably similar.

We now turn to the five subquestions of the study, immediately followed by the main research question.

1. How does sick leave duration compare between homogeneous groups in different regions?

A statistical comparison of the mean duration of sick leave in the two regions showed a difference $(t=-3.94, p<0.001)$ between mean sick leave duration in Southern Limburg (24.61 days; $S D=$ 27.19, $N=80$ ) and in Utrecht (9.56 days; $S D=15.95, N=38$ ). In a number of cases (5 in South Limburg, 14 in Utrecht) the social fund was not able to provide the exact sick leave duration data per individual or these data were not reliable, so that these were missing cases.

2. How do scores of individual sick leave duration determinants compare between homogeneous groups in different regions?

In Southern Limburg as compared to Utrecht, an important although not significant characteristic $(0.05<p<0.10)$ was that the subjects had a perception of poorer health ('health status': health complaints, $p=0.09$ ).

3. How does sick leave duration relate to relevant determinants between homogeneous groups in different regions?
A regression analysis was applied to examine the relation between the selected determinants as independent variables and the mean duration of sick leave as the dependent variable (Table 5).

In Utrecht a longer duration of sick leave was observed if subjects experienced autonomy ('work contents', $p=0.04$ ) and in Southern Limburg if they perceived a poorer health ('questions about perceived health', $p=0.08$ ), an important factor although not significant. In Southern Limburg, a shorter duration of sick leave was observed for women ('individual characteristics and circumstances', gender, $p=0.02$ ). A shorter duration of sick leave was also observed in Southern Limburg if subjects had a burn-out due to their work ('health status': health complaints, $p=0.01$ ) or if they were satisfied with their private circumstances ('individual characteristics and circumstances', $p=0.02$ ).

4. What differences in determinants predicting sick leave duration can be found between homogeneous groups in different regions?

The outcomes of the comparisons that were made to establish any differences in regression coefficients between the two regions led to the conclusion that regional differences existed for the determinants called 'burn-out due to work' $(p=0.01)$, 'gender' $(p=0.01)$ and 'satisfied with private circumstances' $(p=0.01)$.

Thus, the regression analysis showed that regions differed in predictive determinants of sick leave duration and that the regression coefficients for those determinants differed as well, with the exception of the determinant called 'autonomy'.

5. Are the determinants in which regions differ correlated?

Differences between the regions were found for several determinants (subquestion 4). In order to find a possible correlation between those determinants a regression analysis was performed for the health complaints determinants called 'questions about perceived health' and 'burn-out due to work' and the determinants concerning individual characteristics and circumstances called 'age', 'gender' and 'satisfied with private circumstances'. The correlation matrix showed that the determinants 'questions about perceived health' and 'burn-out due to work' were correlated $(0.43, p<0.01)$ as were the determinants 'questions about perceived health' and 'gender' $(0.03, p=0.79)$. The Variance Inflation Factor (range 1.05-1.42) did not show any co-linearity of these determinants.

A missing data analysis showed that the number of missing data affected the results for some determinants. After the imputation operation, some determinants with a substantial number of missings continued to have an inappropriate effect on the results. They were the determinants 'expectations for the future', 'match between work and level of education', 'mental balance', 'alcohol consumption' and 'level of education'. These determinants were excluded from further analysis. Although the box plot showed that several determinants had extremes/outliers, none of them affected the outcome.

The main question of the study was: Are there any differences in the determinants of sick leave duration between homogeneous groups in socio-culturally different regions within a single country and what evidence can be found to suggest an effect of the regional socio-cultural environment?

Based on the results of the statistical analyses it was concluded that, within our country, regional differences in sick leave duration determinants really did exist and that different determinants 
Table 4. Selected determinants, interpretation of scores

\begin{tabular}{|c|c|c|c|}
\hline Independent determinants & $\begin{array}{l}\text { Number } \\
\text { of items }\end{array}$ & Cronbach's $\alpha$ & Meaning of score ${ }^{1}$ \\
\hline \multicolumn{4}{|l|}{ WORKING CONDITIONS } \\
\hline Appreciation for one's work (sum) & 4 & 0.78 & high is more $>$ sds $\mid$ \\
\hline Expectations for the future (sum) & 4 & 0.80 & high is better >sds| \\
\hline Satisfied with one's work (yes=1/no=0) & 1 & & high is more $>$ sds 1 \\
\hline Positive about social-medical support during sick leave (yes=1/no=0) & 1 & & high is more positive: indifferent ${ }^{2}$ \\
\hline Type of appointment (permanent=1/temporary=0) & 1 & & indifferent \\
\hline WORK CONTENTS & 1 & & \\
\hline Autonomy (sum) & 8 & 0.77 & high is more $>$ sds $\mid$ \\
\hline Workload (more work in same amount of time) (yes $=1 /$ no $=0$ ) & 1 & & high is more $>|d s|$ \\
\hline Mental workload (yes=1/no=0) & 1 & & heavier > |ds| \\
\hline Match between work and level of education (yes $=1 / \mathrm{n}_{0}=0$ ) & 1 & & high is better > sdsl \\
\hline \multicolumn{4}{|l|}{ WORKING RELATIONS } \\
\hline Opinion about supervisors (sum) & 9 & 0.90 & high is more positive >sdsl \\
\hline Managers are well informed about the workplace (yes $=1 / \mathrm{no}_{0}=0$ ) & & & high is better $>s d s \mid$ \\
\hline Good atmosphere at workplace (yes $=1 /$ no $=0$ ) & 1 & & high is better $>s d s \mid$ \\
\hline \multicolumn{4}{|l|}{ HEALTH STATUS (perceived workload) } \\
\hline Perceived physical workload (sum) & 10 & 0.77 & high is more $>|d s|$ \\
\hline Perceived mental workload (sum) & 5 & 0.72 & high is more $>|d s|$ \\
\hline \multicolumn{4}{|l|}{ HEALTH STATUS (health complaints) } \\
\hline Questions about perceived health (sum) & 22 & 0.86 & high is more perception of poor health $>|d s|$ \\
\hline Mental balance (sum) & 21 & 0.86 & high is more out of balance $>|d s|$ \\
\hline Burn-out due to work (sum) & 6 & 0.72 & high is more severe $>|d s|$ \\
\hline Annual number of visits (family doctor) & 1 & & more is poorer health $>|d s|$ \\
\hline Frequently taking medicines (yes $=1 / \mathrm{n}_{0}=0$ ) & 1 & & more is poorer health $>|d s|$ \\
\hline \multicolumn{4}{|l|}{ MOTIVATION } \\
\hline Work-related factors (yes $=1 / \mathrm{no}=0$ ) & 1 & & high is more pleasure in work >sds| \\
\hline Home-related factors (sum) & 8 & 0.70 & high is less motivated for work $>|d s|$ \\
\hline \multicolumn{4}{|l|}{ INDIVIDUAL CHARACTERISTICS AND CIRCUMSTANCES } \\
\hline Age & 1 & & older >sds| \\
\hline Gender $(f=1 / m=0)$ & 1 & & female $>|d s|$ \\
\hline Marital status (married=1/not married =0) & 1 & & married $>s d s \mid$ \\
\hline Satisfied with private circumstances (yes $=1 /$ no $=0$ ) & 1 & & more >sds \\
\hline Level of education (high=1; low vocational school level=0) & 1 & & high >sdsl \\
\hline Alcohol consumption (yes=1, no=0) & 1 & & drinking $>|d s|$ \\
\hline Smoking (yes=1, no=0) & 1 & & smoking $>|d s|$ \\
\hline
\end{tabular}

${ }^{1}$ Interpretation of score and - based on the literature review performed - the assumed effect on the duration of sick leave (sds I = shorter duration of sick leave; Ids I = longer duration of sick leave). ${ }^{2}$ Indifferent: literature is scarce or ambiguous. 
Table 5. Results of the regression analyses of sick leave duration determinants per region

\begin{tabular}{|l|c|c|c|c|c|c|}
\hline & Utrecht & & & Southern Limburg & & \\
\hline Determinants: & $\begin{array}{c}\text { Adjusted } \\
\mathbf{R}^{2}\end{array}$ & Beta & Sig & $\begin{array}{c}\text { Adjusted } \\
\mathbf{R}^{2}\end{array}$ & Beta & Sig \\
\hline WORK CONTENTS & $0.09(\mathrm{~N}=25)$ & & & $0.01(\mathrm{~N}=38)$ & & \\
\hline Autonomy & & 0.45 & $0.04 *$ & & 0.12 & 0.50 \\
\hline $\begin{array}{l}\text { HEALTH STATUS: } \\
\text { HEALTH COMPLAINTS }\end{array}$ & $0.003(\mathrm{~N}=32)$ & & & $0.17(\mathrm{~N}=49)$ & & \\
\hline $\begin{array}{l}\text { Questions about perceived } \\
\text { health (sum) }\end{array}$ & & -0.10 & 0.63 & & 0.29 & 0.08 \\
\hline Burn-out due to work (sum) & & 0.09 & 0.66 & & -0.41 & $0.01^{*}$ \\
\hline $\begin{array}{l}\text { INDIVIDUAL CHARACTERISTICS } \\
\text { AND CIRCUMSTANCES }\end{array}$ & $0.06(\mathrm{~N}=35)$ & & & $0.18(\mathrm{~N}=47)$ & & \\
\hline Age & & 0.31 & 0.07 & & 0.18 & 0.18 \\
\hline Gender & & -0.07 & 0.71 & & -0.34 & $0.02 *$ \\
\hline $\begin{array}{l}\text { Satisfied with Private } \\
\text { circumstances }\end{array}$ & & 0.13 & 0.51 & & -0.33 & $0.02 *$ \\
\hline
\end{tabular}

$* p<0.05$

predicted the duration of sick leave in different regions. The potential influence of both socio-cultural factors and European integration is discussed in the next section.

\section{DISCUSSION}

\section{Socio-cultural Characteristics of Southern Limburg in National and Euregional Perspective and the Rela- tion with Health and Sick Leave Behaviour}

As for the assumption that, seen from a socio-cultural perspective, Southern Limburg differs from the rest of the Netherlands, Soeters and Felling (39) observed that Southern Limburg has a different history than the rest of the country because for many centuries it was under the influence of German and Flemish/Wallonian socio-cultural traditions such as a Roman Catholic orientation, whereas the western part of the Netherlands is more of a Calvinistic nature. An indication to suggest some socio-cultural influence from the neighbouring foreign countries is the perception of a poorer health among Southern Limburg residents, as residents of the adjacent Nordrhein-Westfalen also show doubts about their health (22) and therefore visit their doctor more often, as do Southern Limburgers (16). Philipsen (40) and Stevens and Van der Zee (16) assumed that the dominance of Roman Catholic culture in Southern Limburg was a factor that contributed to a less sober lifestyle of Southern Limburg residents. It was expected that Southern Limburg would gradually come to be more like the rest of the country while at the same time, as a result of Euregional influences, it would continue to bear a resemblance with Nordrhein-Westfalen which, together with the border areas of Southern Limburg and the Wallonian province of Limburg, constitutes the Euregion Meuse-Rhine (EMR). As for health perception, the prediction made by Stevens and Van der Zee (16) has come true as recent figures show that residents of Southern Limburg still perceive themselves to be in poorer health than their countrymen (34). A few other important indicators still suggest that socio-cultural factors affected the behaviour of Southern Limburg residents in 2006 the same as they did a few decades earlier. Disability pensions in Southern Limburg continued to exceed those in the rest of the country (17.7\% vs. $11.9 \%)$ and the same applied to unemployment rates (11.3\% vs. $9 \%)$ (35, 41). The differences between Southern Limburg and the rest of the country which have been found since decades include that Limburgers visit their doctor more often, take more medicines, stay longer in hospitals and show higher death rates. More specifically, medical consumption in terms of doctor consultations and the consumption of medicines seems to correspond with the health behaviour of residents in the neighbouring German state of Nordrhein-Westfalen.

As for some socio-cultural characteristics of the Southern Limburg population that were not health-related we observed the following. Socio-cultural differences between Southern Limburg and the rest of the country were found with regard to more collectivism in the Limburg area versus more individualism in the region Utrecht and, especially for youngsters, a stronger orientation on one's partner and family in Southern Limburg as compared to Utrecht $(42,43)$. The SOCON study of 2000 showed some remarkable similarities with the 1985 results $(42,43)$, which suggests a certain continuity in differences in the socio-cultural characteristics of the Southern Limburg population as compared to the rest of the country. Thus it appears that Limburg youngsters still show a stronger tendency to solidarity, i.e. they show a stronger orientation towards groups or social integration. Meanwhile Knibbe (44) has found that people in Limburg still seek continuity with the past in the sense of being part of a community, which is in contradiction with the assumed growth of individualism. As a result, Limburg is still characterised by a 'community spirit', which may be related with the stronger collectivist orientation of Roman Catholic culture, whereas the rest of the country is characterised by a more individualistic and Calvinistic culture. In fact, the more collectivist attitude of Southern Limburg residents is thought to be a factor in the establishment of certain industries in the area (39). As the core of a culture is the less changeable (39), 
an observation supported by recent findings (44), the assumption is that, compared to a more individualistic culture, the collectivist character of Roman Catholic culture still plays a role in the way people in Southern Limburg view life.

\section{The Study Results in the Light of Socio-cultural Characteristics}

A few remarkable results can be mentioned here. Although not significant $(p>0.05)$, the subjects in Southern Limburg as compared to Utrecht had a perception of poorer health ('questions about perceived health', $p=0.09$ ) and the same determinant showed a longer sick leave duration in Southern Limburg ( $p=0.08$ ), the opposite signs of the beta values attributing to the different effect of this determinant in the two regions. This finding concerning the 'questions about perceived health' determinant, a major though not significant characteristic leading to longer sick leave duration in Southern Limburg, corresponds with earlier findings on the health status of Southern Limburg residents $(1,19,35,41)$. Feeling uncertain about one's health is a typical phenomenon of the Southern Limburg population which can also be observed in the adjacent German state of Nordrhein-Westfalen.

As for the outcomes in the Utrecht region, in contrast with the literature (45-48) a greater autonomy at the workplace had an increasing rather than reducing effect on sick leave duration. As the socio-cultural environment is supposed to affect this determinant, a possible explanation for the finding may be that, in the Utrecht area, employees of 20 to 40 years old appreciate 'autonomy' at the workplace in the more individualistic sense that it has a connotation of more freedom rather than more responsibility, whereas employees of the same age in the Southern Limburg area appreciate autonomy as an opportunity to prove their discipline in performing the job in the sense of attributing to the group, an attitude that refers to a more collectivist attitude.

The finding in Southern Limburg that burn-out due to work or being female is associated with a shorter duration of sick leave needs further study regarding burn-out. A possible explanation for the sex difference may be found in the composition of the study sample. In fact, both in Utrecht (73\%) and Southern Limburg (82\%) this profession (cleaning) is practised mainly by women, which may partly explain the finding.

The following Euregional influences were examined. As for health attitude, similarities in behaviour were found between the populations of Southern Limburg and Nordrhein-Westfalen (NRW). In addition, the collectivist Roman Catholic culture was considered to be a lasting factor in the Southern Limburg residents' view of life and to be influenced by the neighbouring Roman Catholic states (Belgium and the German state of NRW) surrounding the region, an influence that is stimulated by the Schengen Treaty (1985). Indeed, like others (49) we expect that open borders will stimulate the maintenance or even growth of foreign socio-cultural influences, especially in this eccentric part of the Netherlands, and that this will find its expression through indicators such as the consumption of health services and claims made for social security. In this context we are fully aware of the paradox that both centrifugal and centripetal powers are active in Euregions. On the one hand central governments strive for European integration, on the other hand they do not want to lose political control over internal regions that are part of Euregions.
This phenomenon does not differ from the time preceding the Schengen Treaty, but the difference is that mutual influences are stronger when open rather than controlled borders are in place. Thus, it makes sense to assume that typical socio-cultural characteristics of (eu)regional populations will be subject to some exchange between these populations. This exchange is expected to find its expression through various economic, cultural and social standards pertaining, for example, to medical consumption or the possibility to claim social security benefits.

\section{METHODOLOGICAL REFLECTIONS}

Topicality of the study for the organisation of social security: Due to changes in the organisation of the social security system in the Netherlands, strict regional registration of sick leave duration has ceased to exist. From 2003 onwards, the Nationale Verzuimstatistiek (15) has been providing sick leave registration per Dutch province and what it shows is that interprovincial differences in sick leave still exist. Moreover, as the present study was carried out during the 1990s, the consistency in determinants predicting duration of sick leave adds to the relevance of its outcome.

Subjects: Subjects for the study were recruited at a time when they reported sick. An alternative approach would have been to study the employees of a few big companies. This would have been a better method to cover the entire group of workers in the cleaning industry. However, for practical reasons it was decided to include only those who reported sick at some point in time. Relevant individual data as well as systematically registered individual absenteeism data could easily be obtained from the social fund. Actually, it would have been a great disadvantage to study the employees of a few big companies because the outcome might be strongly affected by their specific, company-related culture of absenteeism (50, 51).

Small sample size: Although the samples were small, the statistical analyses were performed on study populations that were remarkably similar in nature. As was pointed out earlier and is summarised here, the study populations were homogeneous in age, gender, level of education and profession; their socio-economic circumstances were similar, as was the quality of health services; there was similarity in employment contracts and in the administrative implementation of social security regulations; and, finally, both study populations had similar ethnic backgrounds and originated from areas with a similar mixture of urban and rural qualities.

Number of spells suffered by participants: By starting from a reported case of sick leave when recruiting the study subjects, it would seem as if the participants had at least one spell of sick leave during the study period while so-called 'zero' sick leaves were excluded. This assumption is not correct. The time referred to was the 12-month period preceding the first day of sick leave. Thus, it is possible that participants had a 'zero' duration of sick leave. Furthermore, once people report sick for work they apparently show a greater tendency to have another sick leave than people who never reported sick (52) so the results of this study are representative for those employees who were on sick leave at some point in time rather than for those who never had sick leave before. 
Analysis per category: It would have increased our understanding of the association between determinants and observed sick leave duration if the entire group of selected determinants could be analysed in a single regression analysis. However, a regression analysis of all selected determinants was not a real option. The number of participants actually participating in the analysis $(N)$ would have been quite small due to the number of missing data. This would have made the estimates of the regression analysis unreliable. Thus, for pragmatic reasons the determinants were classified according to the categories they belonged to and then analysed per category. Also, considering the possibility that determinants distinguishing between regions were correlated, a regression analysis for the relevant determinants was performed.

Possible correlations between independent determinants: In interpreting the outcome it should be realised that correlations between independent determinants were not the object of study, although such correlations may exist. In developing a policy to reduce the mean duration of sick leave in a specific region it will be necessary to take into account any correlations between determinants before drawing conclusions.

Study Results and Level of Significance: Some determinants show notable results. This was a reason to consider also $0.05<p<0.10$, in addition to $p<0.05$. After all, using only the $5 \%$ significance level in applied research may be inappropriate (53). Such a conservative approach may provide policy-makers with an unnecessarily incorrect picture, at least when correlations above the $5 \%$ level are not taken into consideration.

Therefore, we have distinguished results for which $p<0.05$ and results for which $0.05<p<0.10$. As was noticed earlier (subquestions 3 and 4 ), $p<0.05$ for most results, except for the determinants 'questions about perceived health' (subquestions 2 and 3) and 'marital status' (subquestion 2). As for the determinant 'questions about perceived health', the opposite sign of the beta values attributes to the difference in effect of this determinant in the two regions and the result is remarkable as it confirms both earlier and later findings $(33,34)$. Furthermore, the small sample size is thought to be the cause of not reaching this significance level.

\section{CONCLUSION}

If a study uses strictly homogeneous groups, i.e. comparable individual and work characteristics and comparable socio-economic conditions, it might be expected that comparable determinants affect sick leave duration in either group. This was not the case and so the results of this study suggest an effect of the regional socio-cultural environment on determinants of sick leave duration in addition to the influence of characteristics such as health status, work situation or professional group. First of all, the results of our study are strongly suggestive of this tendency and they can be generalised to the point that if policy makers intend to take nationwide measures to reduce sick leave duration, they should take into account that determinants predicting sick leave duration may differ per region and that only tailor-made interventions focussed on determinants predicting sick leave duration per region may be effective. The present study investigated socio-culturally different regions under similar social security regulations, assuming that, based on different socio-cultural influences, differences in factors such as health perception may play a role in explaining differences in sick leave duration. In terms of international comparisons, people not only differ in their health perception (Table 1), they are also subject to different social security systems. These observations have consequences for social security policies on a European scale. When regions are part of Euregions, socio-cultural influences of the nearby foreign countries may find their expression in claims made for social security. This phenomenon will last as long as the residents of those regions share socio-cultural characteristics in terms of world view, lifestyle, standards and values. As a result, Euregions in the future could show some substantial similarities with the border regions of adjacent countries which they do not have with their own country. In focussing on sick leave and disability, European as well as national policy-makers of social security should be aware of this phenomenon.

\section{REFERENCES}

1. Beemsterboer W, Stewart R, Groothoff J, Nijhuis, F. On regional differences in duration of sick leave: the role of work, individual and health characteristics. Arch Public Health. 2005;63(6):293-312.

2. LFS. The European Labour Force Survey. Luxembourg: Office for official publications of the European Communities; 2003.

3. Prins R. Sickness absence in Belgium, Germany (FR), and the Netherlands: a comparative study. Maastricht: University of Maastricht; 1990.

4. Halusa G, Oppen M, Buerckhardt D, Schneider M. Regional conditions and sickness absence in Berlin. Berlin: Bundesministerium fuer Forschung und Technologie; 1982. (In German.)

5. Picard J, Mills A. The effect of malaria on work time: analysis of data from two Nepali districts. J Trop Med Hyg. 1992 Dec;95(6):382-9.

6. Vrijhof B, Prins R. Absenteeism in the Netherlands: the most important figures. In: Smulders PGW, Veerman TJ, editors. Absenteeism manual. Guide for business practice. The Hague: Delwel; 1993. p. 33-54. (In Dutch.)

7. Szubert Z, Zycinska Z. Analysis of work absenteeism due to illness in the provinces. Med Pr. 1996;47(2):117-23. (In Polish.)

8. Feeney A, North F, Head J, Canner R, Marmot M. Socioeconomic and sex differentials in reason for sickness absence from the Whitehall II Study. Occup Environ Med. 1998 Feb;55(2):91-8.

9. Virtanen P, Nakari R, Ahonen H, Vahtera J, Pentti J. Locality and habitus: the origins of sickness absence practices. Soc Sci Med. 2000 Jan;50(1):2739.

10. Moncrieff J, Pomerleau J. Trends in sickness benefits in Great Britain and the contribution of mental disorders. J Public Health Med. 2000 Mar;22(1):59-67.

11. Virtanen P, Vahtera J, Nakari R, Pentti J, Kivimaki M. Economy and job contract as contexts of sickness absence practices: revisiting locality and habitus. Soc Sci Med. 2004 Apr;58(7):1219-29.

12. Tordoir W, Van der Klaauw, Van Maanen-Boekestein. Public health and long duration of sick leave. Leiden: NIPG/TNO; 1978. (In Dutch.)

13. Soeters J. Absenteeism in the reconstructed area of Southern Limburg. Maastricht: University of Maastricht; 1980. (In Dutch.)

14. Detam. Figures on sick leave (districts). Utrecht: Detam; 1991.

15. Statistics Netherlands. National registration of absenteeism. The Hague: Statistics Netherlands (CBS); 2006. (In Dutch.)

16. Stevens F, Van der Zee J. Health care in national and Euregional perspective. In: Soeters J, Spoormans H, Welten R. Renewed Limburg. Reconstruction and development. Schiedam: Scriptum; 1990. (In Dutch.)

17. Bloemberg B, Doornbos G, Van Oostrum M. Regional health profiles. Bilthoven: National Institute of Public Health and the Environment (RIVM); 1993. (In Dutch.)

18. Statistics Netherlands. Permanent Study of Life Conditions. The Hague: Statistics Netherlands (CBS); 1993. (In Dutch.)

19. Municipal Health Services Limburg. Mortality in Limburg: trend report 1985-1999. Limburg: Municipal Health Services Limburg; 2005. (In Dutch.)

20. Statistics Netherlands. Health characteristics and medical consumption after Municipal Health Services. The Hague: Statistics Netherlands (CBS); 2006. (In Dutch.) 
21. Hofstee E. Growth of the Dutch population. In: den Hollander AN. Temper and course. Half a century of social change in the Netherlands. Assen: Van Gorcum; 1962. p. 13-85. (In Dutch.)

22. Hofstede G. Culture's consequences, international differences in workrelated values. London: Sage; 1980.

23. Van Deursen C, Smulders P, Bongers, P. Does poor health predict absenteeism? Tijdschr Soc Gezondheidsw. 1997;75(4):157-64. (In Dutch.)

24. Boot CR, van der Gulden JW, Orbon KH, Vercoulen JH, Akkermans R, van Weel C, et al. Asthma and chronic obstructive pulmonary disease: differences between workers with and without sick leave. Int Arch Occup Environ Health. 2004 Jun;77(5):357-62.

25. De Groot M. Quantitative approach of absenteeism of Dutch factory workers with neurosis. Leiden: NIPG/TNO; 1958. (In Dutch.)

26. Philipsen H. Absence due to illness. Groningen: Wolters-Noordhoff; 1969. (In Dutch.)

27. Veerman T. Theoretical models on absenteeism. In: Smulders PGW, Veerman TJ, editors. Absenteeism manual. Guide for company practice. The Hague: Delwel; 1993. (In Dutch.)

28. Nijhuis F, Soeters J. Work and illness: a study of absenteeism due to illness and incapacity for work in 51 companies in Southern Limburg. Maastricht: University of Maastricht; 1982. (In Dutch.)

29. Smulders P. Balance of 30 years of research on sickness absence: results of 318 studies summarized. Leiden: NIPG/TNO; 1984. (In Dutch.)

30. Grosfeld J. The predictability of individual sick leave duration. Amsterdam: Swets and Zeitlinger; 1988. (In Dutch.)

31. Klein Hesselink D, Kruidenier H, Veerman T, Buijs P. Absenteeism explained. A literature search on determinants of sick leave and incapacity for work. Amsterdam: NIA; 1993. (In Dutch.)

32. Dutch National Atlas of Public Health [Internet]. Bilthoven: National Institute for Public Health and the Environment (RIVM); 2004 [cited 2009 Mar 15]. Available from: http://www.rivm.nl/vtv/object_document/o6990n22311.html.

33. Bisscheroux P, Nijhuis J, Kruijnen M, Knipschild P, Limonard C. Health Vademecum Limburg. Maastricht: MEMIC; 1986. (In Dutch.)

34. National Public Health Compass. Bilthoven: RIVM; 2006. (In Dutch.)

35. Institute for Employee Insurances. Social insurance atlas 2003-2005. Amsterdam: UWV; 2005. (In Dutch.)

36. De Winter CR. Work, health and absenteeism as predictors of disability pension. Maastricht: University of Maastricht; 1991. (In Dutch.)

37. Cortina J. What is coefficient alpha? An examination of theory and applications. J Appl Psychol. 1993 Feb;78(1):98-104.

38. Zar JH. Biostatistical analysis. 4th ed. New Jersey: Prentice-Hall International; 1999.

39. Soeters J, Felling, A. Limburg’s own. In: Soeters J, Spoormans H, Welten R. Renewed Limburg. Reconstruction and development. Schiedam: Scriptum; 1990. (In Dutch.)

40. Philipsen H. Health and health care in Belgium. Some snags in the supposedly green grass of a system comparison. Gezondheid Samenleving. 1985;6:228. (In Dutch.)
41. Limburg in figures. Maastricht: Province of Limburg, Department for Strategy and Innovation; 2006. (In Dutch.)

42. Dans easy: data-archiving system [Internet]. The Hague: The Netherlands; 1995 [cited 2009 Mar 15]. Felling A, Peters J, Schreuder, O. Socio-cultural developments in the Netherlands]. SOCON 1985. P1012. Available from: http://easy.dans.knaw.nl/dms?command=show\&didAction=\&query=ver anderingen\&sortColumn=\&windowStyle=default. (In Dutch.)

43. Dans easy: data-archiving system [Internet]. The Hague: The Netherlands; 2000 [cited 2009 Mar 15]. Eisinga R, Coenders, M. Socio-cultural developments in the Netherlands. SOCON 2000. P1556. Available from: http://easy.dans.knaw.nl/dms?command=show\&didAction=\&query=ver anderingen\&sortColumn=\&windowStyle=default. (In Dutch.)

44. Knibbe K. Faith in the familiar: continuity and change in religious practices and moral orientations in the South of Limburg, the Netherlands. Amsterdam: Vrije Universiteit; 2007.

45. Karasek R. Lower health risk with increased job control among white collar workers. J Organ Behav. 1990;11:171-85.

46. Greiner BA, Krause N, Ragland DR, Fisher JM. Objective stress factors, accidents, and absenteeism in transit operators: a theoretical framework and empirical evidence. J Occup Health Psychol. 1998 Apr;3(2):13046.

47. Shain M. The role of the workplace in the production and containment of health costs: the case of stress-related disorders. Int J Health Care Qual Assur Inc Leadersh Health Serv. 1999;12(2-3): i-vii.

48. Ala-Mursula L, Vahtera J, Kivimäki M, Kevin MV, Pentti, J. Employee control over working times: associations with subjective health and sickness absences. J Epidemiol Community Health. 2002 Apr;56(4):272-8.

49. Soeters J, Spoormans H, Welten R. Limburg, now and further. In: Soeters J, Spoormans H, Welten R. Renewed Limburg. Reconstruction and development. Schiedam: Scriptum; 1990. (In Dutch.)

50. Chadwick-Jones J, Nicholson N, Brown C. Social psychology of absenteeism. New York: Praeger; 1982.

51. Nicholson N, Johns G. The absence culture and the psychological contract: who's in control of absence? Acad Manage Rev. 1985;10(3):397-407.

52. Van Deursen C, Reuling A, Veerman T. SZW-Forum of Employers 1998-1999, absenteeism, work circumstances, reintegration, incapacity to work. The Hague: Ministry of Social Affairs and Employment/Elsevier Bedrijfsinformatie; 2000. (In Dutch.)

53. Plantenga J. The choice of significance level in policy-making socioscientific research. Sociologische Gids. 1981;28. (In Dutch.)

Received March 15, 2009 Accepted in revised form November 10, 2009 